\title{
Tecnologia da Comunicação e Mediação Social: O Papel da Telefonia Celular na Amizade Entre Adolescentes
}

\author{
Hugo Cristo Sant'Anna, \& Agnaldo Garcia* \\ Universidade Federal do Espírito Santo, Vitória, Brasil
}

\begin{abstract}
RESUMO
A presente pesquisa investigou a percepção do papel da telefonia celular nas relações de amizades de adolescentes. Vinte adolescentes (dez do sexo masculino e dez do sexo feminino) com idades entre 14 e 17 anos participaram da pesquisa. Os dados foram coletados por meio de questionários e entrevistas e discutidos de acordo com a perspectiva de Robert Hinde. Com o uso do celular houve ampliação no tempo de contato, na quantidade de informações trocadas e na diversidade de situações em que tornase possível comunicar-se com amigos, sendo o planejamento de atividades o uso mais freqüente do equipamento. O celular permitiu aumentar a rede de amigos e provocou mudanças nas relações já existentes. A satisfação com as amizades, a intimidade e a proximidade aumentaram, assim como as possibilidades de dar e receber apoio.
\end{abstract}

Palavras-chave: amizade; adolescência; telefonia celular.

\section{ABSTRACT \\ Communication Technology and Social Mediation: The Role of Cell Phones in Friendship Among Adolescents}

This study investigated how adolescents perceive the use of the cell phone in their relationships with friends. Twenty adolescents (ten boys and ten girls) with ages ranging from 14 to 17 years old participated. Data were collected using questionnaires and interviews and they were discussed according to the perspective of Robert Hinde. The cell phone enabled adolescents to increase the time in contact with friends, the amount of information exchanged and the diversity of situations in which friends were contacted, and it is used mainly to plan activities with friends. It allowed adolescents to increase the number of friends and affected pre-existing relationships. Satisfaction with friendships, opportunities to give and receive support, intimacy and closeness with friends increased after the use of the cell phone.

Keywords: friendship; adolescence; cell phone.

De acordo com Hinde (1997), a amizade não é fácil de definir, sendo vista de modo diverso em diferentes culturas, por homens e mulheres, e mesmo dentro de uma mesma cultura. A amizade, como relacionamento positivo e voluntário, é caracterizada por aspectos como autorrevelação, confiança, percepção interpessoal e compromisso, não sendo definida por aquilo que os participantes fazem juntos. Geralmente, tratase de um relacionamento diádico, embora três ou mais pessoas possam ser amigos mútuos. A maioria das amizades influencia e é influenciada pelo grupo em que se insere e sua natureza voluntária também é motivo de fragilidade. Desde a infância, há a tendência para fazer amigos com parceiros do mesmo sexo, provavelmente devido a preferências por atividades e há diferenças de natureza nas amizades de homens e de mulheres. Amizades dependem da compatibilidade entre os parceiros e sofrem mudanças ao longo da vida. Para Hinde, a essência da amizade possivelmente esteja relacionada com o sentimento de conforto, liberdade e naturalidade das emoções entre amigos. $\mathrm{O}$ autor ainda aponta como elemento essencial desta

\footnotetext{
Endereço para correspondência: Agnaldo Garcia, ACF/Campus Universitário, Caixa Postal 9008, Vitória, ES, CEP $29075-973$. E-mail: agnaldo.garcia@uol.com.br.
} 
forma de relacionamento que os dois parceiros se mantenham atualizados acerca das ações do outro, destacando a importância do conhecimento compartilhado. Finalmente, amizades diferem em proximidade e estão sujeitas a tensões.

Segundo Fehr (1996), amizades são um aspecto central de nossas vidas, em cuja formação entram fatores ambientais, individuais, situacionais e diádicos, apresentando diferentes níveis de proximidade, como amigos, amigos próximos e melhores amigos e também apresenta diferenças de gênero. A autora enfatiza processos relacionados à formação, manutenção, deterioração e dissolução da amizade.

Apesar de a amizade entre adolescentes ser um tema amplamente investigado no exterior, os trabalhos relacionando amizade e adolescência ainda são escassos no Brasil. Entre estes destacam-se dois artigos sobre a amizade de adolescentes em relação a problemas de saúde ou deficiência. Garcia (2002) realizou uma revisão da literatura relacionando amizade, enfermidade e deficiência na infância e na adolescência. Ferreira e Garcia (2008) investigaram aspectos da amizade de adolescentes portadores de diabetes e câncer, analisando os efeitos da enfermidade sobre suas amizades, concluindo que a presença do câncer e do diabetes levou a um aumento do apoio social. A autorrevelação e a intimidade sofreram restrições em relação a conteúdos ligados à enfermidade. Segundo os autores, o afastamento ou aproximação dos amigos pode resultar da identificação ou diagnóstico de uma doença como câncer ou diabetes.

A amizade na adolescência é um processo de grande importância na formação social do indivíduo. Urberg, Degirmencioglu e Tolson (1998) sugerem que, ao escolherem um amigo ou grupo de amizades, os adolescentes escolhem um contexto onde aprenderão habilidades, além de influenciarem e serem influenciados por outros adolescentes. A percepção de similaridade entre os indivíduos opera nesse contexto como uma forma de auxiliar nas escolhas das amizades, uma vez que os valores e atitudes do amigo em potencial podem não estar disponíveis para serem observados. Segundo Akers, Jones e Coyl (1998), a similaridade é um dos fatores centrais nas amizades, atingindo status, comportamentos, atitudes e intenções.

Outro ponto fundamental das amizades é a comunicação entre amigos na adolescência (Feldstein \& Field, 2002) com um aumento da compreensão mútua (Enomoto, 1999). O conflito está presente na relação entre amigos (Adams \& Laursen, 2001) assim como a agressividade (Crothers, Field, \& Kolbert, 2005), que pode resultar da influência de amizades agressivas e da agressão pelo amigo (Adams, Bukowski, \& Bagwell, 2005).

De acordo com as particularidades de cada cultura, os amigos juntamente com a família se apresentam como as principais fontes de apoio social para o adolescente (French, Rianasari, Pidada, Nelwan, \& Buhrmester, 2001). Nesse sentido, os melhores amigos desempenham papel particularmente importante ao proverem oportunidades de aceitação, respeito, confiança, intimidade, diversão, espontaneidade, estabilidade e autoexposição (Cole \& Bradac, 1996). Para Giordano (1995), a adolescência, quando comparada à infância, apresenta um círculo mais amplo de amigos, oferecendo oportunidades para que o indivíduo avalie seus relacionamentos em redes sociais cada vez maiores. Nessa fase, segundo o autor, são temas centrais de investigação fatores como continuidade, mudança, distância e proximidade. Allan (2001) cita a importância dos amigos e da rede de relacionamentos na ratificação e confirmação das escolhas dos indivíduos no que diz respeito ao seu estilo de vida frente às mudanças no ambiente social e econômico. Nesse sentido, a investigação das amizades no ambiente escolar parece ser de grande interesse (Lannengrand, 1998).

A incorporação da telefonia celular ao dia a dia da população mundial já é uma realidade. De acordo com dados de 2005, da International Telecommunications Union, mais de 738 milhões usuários utilizam celulares muitas vezes dotados de recursos muito superiores aos encontrados em computadores usados há pouco mais de 10 anos, tornando-se um dos principais símbolos da tecnologia da sociedade pós-moderna. O ritmo intenso característico da vida nos grandes centros urbanos somado à alta velocidade de circulação de informações parece configurar o campo ideal para o desenvolvimento da telefonia celular. Em um único dispositivo de propósitos múltiplos (Hulme \& Peters, 2002) e de dimensões cada vez mais reduzidas encontram-se disponíveis um número cada vez maior de facilidades: relógio com alarme, agenda pessoal, secretária eletrônica, jogos, câmera fotográfica digital, serviços de envio de mensagens de texto e imagem, GPS (sistema de localização), Internet sem fio, entre outros. A evolução da telefonia celular nos faz crer que a função primária dessa tecnologia (fazer e receber chamadas) já não é o único atrativo para seus milhões de usuários. 
O telefone celular tem aumentado sua influência no meio social. Srivastava (2005) argumenta que os telefones celulares permitem aos usuários estar em casa o tempo todo, independentemente de onde se encontram no espaço físico. Segundo o autor, na telefonia fixa, uma ligação toca em um lugar definido, não importando quem esteja sendo chamado, enquanto, na telefonia celular, a própria pessoa seria chamada, não importando o lugar. Nesse sentido, o celular passaria a ser associado à identidade do indivíduo, enquanto, no caso telefone fixo, a localização geográfica desempenharia esse papel.

Questões semelhantes sobre a relação entre identidade, papéis sociais e espaço físico são discutidas por Truch e Hulme (2004), ao abordarem mudanças a partir da substituição da telefonia fixa pela celular na organização das atividades diárias. Segundo os autores, a comunicação entre indivíduos e sua rede social, assim como o conseqüente desempenho de determinados papéis sociais, eram originalmente definidos pela desconexão física, ou seja, pelas pausas, ou sensações de presença e ausência do indivíduo dentro de sua rede de relacionamentos. Nesse contexto, o indivíduo permaneceria identificado com um determinado papel até que o próximo papel fosse assumido, fazendo com que fosse reconhecido e categorizado nos espaços públicos através desse comportamento visivelmente identificável. A partir da introdução da comunicação celular, os autores argumentam que haveria uma quebra da linearidade na sucessão de papéis e a conseqüente dominância da simultaneidade de papéis e abstração das limitações do espaço físico. Srivastava (2005) ainda sugere que a telefonia celular tende a enfraquecer laços mantidos com comunidades ou grupos pré-determinados e mais estáticos e a fortalecer redes descentralizadas e em desenvolvimento constante, organizadas pelos próprios indivíduos. No que diz respeito aos espaços público e privado, pode-se dizer que a distinção entre as duas esferas é cada vez menos evidente.

Plant (2001) defende a idéia de que os celulares criaram uma simultaneidade de espaços que consistiria em um espaço físico e um espaço virtual de interações conversacionais, ou ainda que o espaço físico foi estendido através da criação e justaposição de um espaço social celular. Srivastava (2005) fala em uma intimidade tecnológica, referindo-se ao fato de que o indivíduo leva o celular consigo para todos os lugares, em diversas situações sociais ou profissionais, indo ao encontro de resultados de pesquisas que já apontam o celular como uma extensão do corpo humano e, consequentemente, do self (Davide, Dario, \& Tal , 2004; Hulme \& Peters, 2002; Lemish \& Cohen, 2005; Pertierra, 2005).

Uma outra questão que precisa ser abordada diz respeito às formas de comunicação que são empregadas por intermédio do celular. O celular enquanto objeto é utilizado para evidenciar relações de pertencimento a determinados grupos sociais ou mesmo para comunicar traços da identidade do seu proprietário. Ao mesmo tempo, a conversação utilizando o aparelho não está restrita à voz, podendo ser realizada de diversas formas. Considerando este nível mais elementar de comunicação (a conversação efetiva entre dois indivíduos) é nas mensagens de texto que podemos observar o desenvolvimento de uma forma particular de interação bastante curiosa. Os usuários digitam mensagens com até 160 caracteres utilizando o próprio teclado alfanumérico do celular e enviam para outro aparelho, com diversas finalidades. No Japão, por exemplo, é comum enviar uma mensagem de texto antes de efetuar uma chamada de voz, visando confirmar que a pessoa estará em condições de atender à ligação ("Young "prefer texting to calls", 2003). Entre os jovens, é comum o envio de mensagens de texto durante as aulas, no caminho da escola para casa, ou mesmo em casa enquanto realizam atividades diárias (banho, refeições): o importante é manter-se disponível para seu círculo de amizades (Ling \& Yttri, 2003).

Pensando o celular como objeto, podemos dizer que as pessoas tenderiam a exibir seus celulares em lugares públicos como parte da imagem que pretendem projetar de suas identidades, fazendo com que as escolhas dos elementos externos - cor, forma, tamanho, modelo, acessórios, adesivos - e internos - toques, papéis de parede, jogos, número de mensagens e ligações recebidas dos amigos - que compõem a percepção geral do dispositivo pelos demais indivíduos, não sejam feitas ao acaso (Srivastava, 2005). Homens e mulheres tendem a demonstrar comportamentos diferenciados ao exibirem celulares, assim como pares ou grupos compostos por homens e mulheres, apenas mulheres ou apenas homens, conforme observou Plant (2001).

Bolter e Grusin (1999) sugerem o termo remediação para explicar como os novos meios de comunicação não só absorvem e superam como também modificam os meios que os antecederam. Partindo dessa 
abordagem, o telefone celular não apenas sucederia o fixo, mas também transformaria a existência deste no meio social. Guattari e Rolnik (2005) apresentam argumentos similares, ao sugerirem que as novas tecnologias não se limitam a melhorar ou otimizar as formas de comunicação, mas estabelecem novas relações comunicativas, produzem novas subjetividades, agenciam os indivíduos na estrutura social.

Pode-se concluir que o mundo dos relacionamentos mediados pela telefonia celular apresentaria interações distintas daquelas existentes em outros contextos, não apenas quando o dispositivo se faz presente, mas nas interações como um todo. Ling (2000) sugere que o celular permite que o adolescente esteja virtualmente disponível 24 horas por dia para a sua rede de amigos, garantindo sua participação ativa e constante em suas atividades. Ling e Yttri (2003) definem microcoordenação como a possibilidade do adolescente reorganizar constantemente suas atividades diárias por meio do celular com sua rede de amigos, pais e parentes e hiper-coordenação os usos ligados à expressividade e socialização dos celulares entre os jovens. Rivière (2002) discute em profundidade o uso de $S M S$ (mensagens curtas) entre amigos, sugerindo que essa forma seria também uma forma criativa e plural de comunicação verbal e não verbal. As mensagens curtas abririam espaço para o emprego de emoticons e smileys, símbolos gráficos compostos por letras que carregam significados expressivos - tristeza, felicidade, curiosidade, etc. - permitindo que os indivíduos enviem mensagens cujo sentido vai além do texto, estabelecendo conexões com todo relacionamento já vivido. Ao contrário da conversa via voz, no $S M S$ os amigos podem receber uma mensagem discretamente, refletir e responder não importando onde estejam. Nesse sentido, as mensagens de texto agem para manter contato constante com amigos, não sendo necessariamente relacionadas a eventos específicos ou conversas iniciadas com propósitos definidos.

O desenvolvimento de redes sociais por meio de mensagens de texto apresenta um crescimento menor que o observado por meio de relações face a face, com as garotas adolescentes apresentando uma tendência maior para a expansão de suas redes sociais que os rapazes, em ambos os casos (Igarashi, Taki, \& Yoshida, 2005). Os autores ainda observaram que a intimidade entre os amigos que se comunicavam por ambos os meios era maior que a encontrada entre aqueles que se comunicavam somente face a face.
Berg, Taylor e Harper (2003) afirmam que o celular faz com que os adolescentes se deparem com as obrigações sociais das trocas: dar, receber e corresponder. Não responder uma mensagem de texto pode gerar conflitos ou insatisfação entre amigos, de mesma forma que não retornar uma chamada poderia incomodar amigos que se comunicam através do telefone fixo. Campbell e Russo (2003) citam um estudo realizado em nove países europeus que propôs a existência de uma relação significativa entre as características da rede social e o uso dos meios de comunicação: membros de redes sociais mais duradouras, espacialmente localizadas, confiam mais em encontros face a face e ligações via telefone fixo. Por outro lado, redes sociais que fazem uso de celulares, SMS e $e$ mail seriam compostas mais por amigos que membros de famílias.

No entanto, segundo Srivastava (2005), para muitos jovens, não há diferença entre falar ao celular e encontrar alguém face a face, uma vez que a tecnologia teria se tornado a principal forma de socialização dos adolescentes em diversos países industrializados. Para esse autor, o aumento na quantidade de formas de comunicação não representou um aumento paralelo na qualidade das interações. Embora a conversação por mensagens de texto possa ser rica em significados que transcendem o texto, são pobres nos demais elementos da comunicação humana: linguagem corporal, expressões faciais e toque. $\mathrm{O}$ autor afirma que muitos jovens, em seu estudo, preferiam a conversação via SMS especialmente em situações de conflito ou emocionalmente carregadas.

Segundo Kasesniemi e Rautiainen (2003), o estilo de comunicação dos adolescentes via $S M S$ pode ir de encontro ao seu estilo pessoal de comunicação, de forma que essa diferença poderia ter consequências no início e manutenção de relacionamentos. Um adolescente pode ter uma personalidade forte, extrovertida, via $S M S$, e ser mais reservado pessoalmente. Apesar da existência de investigações sobre os efeitos da telefonia celular sobre as redes sociais de adolescentes, ainda faltam pesquisas sobre a relação entre amizades e telefonia celular, especialmente no contexto sulamericano.

Hinde $(1979,1987,1997)$ enfatiza a importância da descrição no estudo dos relacionamentos, com a consideração de sucessivos níveis de complexidade, desde o indivíduo, passando por interações, relacionamentos, grupos até a sociedade e pela consideração 
das relações dialéticas entre estes níveis e o ambiente físico e a estrutura sociocultural. Para o autor, a comunicação é a essência dos relacionamentos, levandonos a considerar não apenas interações presenciais diárias como objetos de análise relevantes, mas também qualquer forma de comunicação entre os indivíduos mediada pelos diversos meios de comunicação contemporâneos. De acordo com o esquema proposto por Hinde (1997), a telefonia celular pode ser considerada parte da estrutura sociocultural (como tecnologia, ao lado de crenças, valores, instituições, entre outros) que transforma o ambiente físico. O telefone celular, como objeto que incorpora tecnologia afeta diretamente a vida social dos adolescentes e, especificamente, suas relações de amizades. A influência, contudo, dá-se nos dois sentidos e os relacionamentos demandam da tecnologia inovações constantes.

$\mathrm{O}$ avanço tecnológico dos meios de comunicação tem modificado as possibilidades de comunicação entre amigos. Assim, torna-se importante investigar, do ponto de vista de uma ciência dos relacionamentos, como essas mudanças afetam as relações entre as pessoas. Isto não se limita à telefonia celular, mas a todas as novas tecnologias que interferem no contato entre as pessoas.

O objetivo da presente pesquisa foi investigar como adolescentes percebem a influência da mediação da telefonia celular em suas amizades, tomando por base algumas categorias ou dimensões de análise tradicionalmente empregadas nos estudos sobre o relacionamento, em geral, e sobre a amizade, em particular.

\section{MÉTODO}

\section{Participantes}

Vinte adolescentes de quatro escolas particulares do município de Vitória (ES), sendo dez rapazes entre 14 e 17 anos e dez garotas entre 14 e 16 anos, estudantes da oitava série do ensino fundamental ao terceiro ano do ensino médio responderam a um questionário sobre o uso do celular e, em seguida, foram entrevistados individualmente. Os adolescentes pertenciam a famílias de nível sócioeconômico médio, sem qualquer transtorno de desenvolvimento aparente, problemas de comportamento ou problemas de aprendizagem na escola.

Em relação às escolas, a primeira era de pequeno porte e direcionada a famílias de nível socioeconômi- co médio e alto, oferecendo turmas desde o ensino fundamental até o pré-vestibular, em horário semiintegral ou integral. A segunda escola era de médio porte e direcionada a famílias de nível socioeconômico médio, oferecendo na unidade visitada apenas turmas de ensino médio e pré-vestibular em período parcial. A terceira escola tinha perfil similar à segunda. A quarta escola era administrada por religiosos e direcionada a famílias de nível socioeconômico médio e alto, oferecendo turmas do ensino fundamental ao prévestibular, em período parcial. Os adolescentes da primeira escola estudavam em regime integral, enquanto os demais eram todos estudantes do período matutino.

As quatro escolas eram estabelecimentos tradicionais de ensino no Estado, com mais de 20 anos de existência. As três primeiras eram de natureza laica. Todas estavam estabelecidas em bairros predominantemente residenciais do município. Estas escolas foram selecionadas em função da expectativa de um uso mais amplo da telefonia celular entre estudantes com uma renda maior. Os adolescentes participantes foram selecionados com base na idade (entre 14 e 17 anos), incluindo alunos do final do ensino fundamental $\mathrm{e}$ ensino médio, e com base no uso habitual do telefone celular.

Os estudantes primeiramente completaram os questionários e, em seguida, foram entrevistados na própria escola. Todos os participantes que preencheram o questionário participaram das entrevistas. As entrevistas foram gravadas e posteriormente transcritas na íntegra. A coleta de dados e a transcrição dos dados foram realizadas por um dos autores, como parte de sua dissertação de mestrado. A elaboração e análise das categorias foram discutidas pelos dois autores. As questões foram baseadas em estudos empíricos conduzidos previamente, permitindo o uso de algumas categorias previamente estabelecidas. $\mathrm{O}$ questionário era de múltipla escolha e a entrevista estava baseada em questões abertas.

\section{Instrumentos}

O questionário sobre o uso do celular (Anexo A) tinha o objetivo de identificar os hábitos dos adolescentes com o dispositivo no dia-a-dia, incluindo (a) informações sobre aquisição e uso do celular; (b) opiniões sobre os celulares em geral; (c) recursos utilizados do aparelho; (d) o celular e a comunicação com 
amigos. As entrevistas investigaram a influência do celular em suas amizades, tomando por base algumas categorias ou dimensões da amizade, selecionadas em função da possível influência que sofrem pelo uso desse meio de comunicação.

As entrevistas semiestruturadas seguiram um roteiro previamente estabelecido com 25 questões (Anexo B) e foram realizadas em sala reservada durante $o$ período de aula. As entrevistas foram transcritas e organizadas de acordo com os seguintes itens: (a) uso da telefonia celular e a comunicação interpessoal com amigos; (b) efeitos do uso do celular na rede de amigos e nas atividades compartilhadas com estes; (c) efeitos do sobre a satisfação com as amizades e apoio dado e recebido; (d) influência do dispositivo na intimidade e proximidade com amigos.

\section{Procedimentos e análise dos dados}

Os dados foram analisados por análise de conteúdo, com base em Bardin (1977). Os dados do questionário foram tabulados e uma síntese dos principais resultados é apresentada. Dentro de cada item investigado foram utilizadas categorias prévias (de acordo com estudos anteriores) ou eram propostas a partir das respostas.

O projeto de pesquisa foi submetido ao Comitê de Ética em Pesquisa do Programa de Pós-Graduação em Psicologia da UFES, tendo sido aprovado, e os jovens e seus pais e/ou responsáveis assinaram um termo de consentimento para participação na pesquisa.

\section{RESULTADOS}

Os resultados apresentados a seguir são provenientes de duas fontes: questionários e entrevistas semiestruturadas.

Os adolescentes começaram a utilizar o celular por volta dos 11 ou 12 anos. O aparelho era utilizado basicamente para receber chamadas de amigos, sendo os recursos mais utilizados as mensagens de texto, chamadas de voz e agenda. Em relação à rede de amizades, não viam problemas em fornecer o telefone de um amigo para outros amigos e utilizavam os celulares de amigos em caso de necessidade. Quando os amigos utilizavam seus celulares estavam autorizados a verificar mensagens e fotos recebidas e enviadas, chamadas recebidas e realizadas, mas não podiam levá-lo em viagens, trocá-lo ou tomá-lo emprestado sem permissão.

O conteúdo das entrevistas foi organizado em quatro tópicos: (a) papel do celular na comunicação com amigos (Tabela 1); (b) uso do celular e mudanças na rede de amigos e nas atividades compartilhadas com eles (Tabela 2); (c) mudanças na satisfação com o relacionamento e apoio social (Tabela 3); (d) o papel do celular na proximidade e intimidade com os amigos (Tabela 4). Os resultados se referem à percepção dos participantes sobre o uso do celular e as relações de amizade.

Conforme indicado na Tabela 1 , o celular afeta a comunicação com amigos de diversas formas.

Tabela 1

o Uso da Telefonia Celular e a Comunicação Interpessoal com Amigos

\begin{tabular}{|c|c|c|c|}
\hline & Rapazes & Garotas & Total \\
\hline Afetou os temas das conversas com amigos & 5 & 1 & 6 \\
\hline Não afetou os temas das conversas com amigos & 5 & 9 & 14 \\
\hline Aumentou a quantidade de informação trocada & 7 & 4 & 11 \\
\hline Não alterou a quantidade de informação & 3 & 6 & 9 \\
\hline Permitiu falar com amigos em situações inéditas & 9 & 10 & 19 \\
\hline Permitiu falar mais tempo com amigos diariamente & 10 & 10 & 20 \\
\hline Preferem o uso de chamadas de texto & 1 & 7 & 8 \\
\hline Preferem o uso de chamadas de voz & 9 & 3 & 12 \\
\hline O celular representa até $20 \%$ do tempo que se comunica com amigos & 6 & 5 & 11 \\
\hline O celular representa entre $20 \%$ e $40 \%$ do tempo que se comunica com amigos & 3 & 4 & 7 \\
\hline O celular representa entre $40 \%$ e $50 \%$ do tempo que se comunica com amigos & 1 & 1 & 2 \\
\hline
\end{tabular}


O celular, em alguns casos, promoveu uma seletividade de temas de conversas, levando os adolescentes a evitar alguns temas. Houve um aumento do tempo em contato com os amigos, da diversidade de situações na qual o contato é possível, além da quantidade de informações trocadas, que diferiu entre rapazes e garotas. Os rapazes utilizavam o celular de modo mais pragmático (para combinar ações com amigos) e as garotas de modo mais amplo, trocando informações pessoais (novidades e fofocas), sobre eventos sociais (festas e shows), ambientes sociais que freqüentam (como escola), sobre pessoas (incluindo garotos e namorados), urgências, roupas, além de combinar ações com amigos. Enquanto os rapazes preferem as chamadas de voz, as garotas preferem as de texto. O único ponto negativo apontado para a comunicação celular foi a possibilidade de este estar desligado, impossibilitando o contato com o amigo.
O aumento do tempo, da quantidade e das situações em que a comunicação é possível resulta na percepção do aumento da disponibilidade como a influência mais importante do celular nas amizades, tornando possível compartilhar informações com os amigos no mesmo instante, achar as pessoas em qualquer lugar e estar sempre acessível: “(...) tem coisas que acontecem e aí eu quero, pô, lembrei da minha amiga, quero falar pra ela o que aconteceu agora" (sexo feminino, 16 anos); “(...) quando tem alguma coisa pra falar, ao invés de deixar pra falar depois, eu ligo" (sexo masculino, 14 anos). O celular serve para ligar para amigos para reportar acontecimentos importantes. A comunicação pelo celular aproxima e informa os amigos: "eu ligo pra elas o tempo todo, mas elas também me ligam o tempo todo" (sexo feminino, 16 anos, referindo-se às três melhores amigas).

Conforme indicado na Tabela 2, o uso do celular afetou a rede de amigos e as atividades compartilhadas com eles.

Tabela 2

Rede de Amigos e Atividades - Efeitos do Uso de Celular

\begin{tabular}{|c|c|c|c|}
\hline & Rapazes & Garotas & Total \\
\hline Aumentou o número de amigos & 2 & 2 & 4 \\
\hline Não alterou o número de amigos & 8 & 8 & 16 \\
\hline Alterou as amizades já existentes & 2 & 5 & 7 \\
\hline Não alterou as amizades já existentes & 8 & 5 & 13 \\
\hline Serve para planejar atividades antes do encontro & 10 & 10 & 20 \\
\hline
\end{tabular}

Em alguns casos, o uso do celular aumentou o número de amigos, levando à inclusão de novas pessoas à rede social do adolescente: “(...) conheci amigos de amigos através do celular. Eu liguei para um amigo aí outro atendeu, aí acabei conhecendo" (sexo feminino, 16 anos). Em relação às amizades já existentes, houve ampliação das possibilidades de contato, aproximação e intensificação da comunicação com aumento no volume de informações trocadas: “(...) conheci amigos através de outras pessoas e depois com o celular e envio de mensagens fiquei mais amigo" (sexo feminino, 15 anos); “(...) eu consigo conversar com pessoas que não consigo encontrar" (sexo masculino, 17 anos).

O uso mais comum do celular foi no planejamento das atividades. O aparelho é usado para marcar o motivo, local e hora para sair, para avisar a saída e che- gada ao local marcado e informar atrasos. No caso de alguém se perder, para combinar um local para o reencontro. Ainda serve para organizar o retorno para casa. Durante a realização das atividades combinadas, o celular ainda permite desencadear novas atividades ou reorganizar as já definidas. "Mudou, porque agora quando a gente vai sair ou alguma coisa assim, é tudo combinado pelo celular. Um torpedo você pode escrever uma vez e mandar pra um monte de gente... Quem tiver celular vai, que não tiver celular ou tiver com celular desligado fica por fora, fica em casa dormindo" (sexo masculino, 16 anos). O celular também permite informar o amigo sobre atividades de interesse: "estou no shopping esperando meu namorado chegar, aí eu lembro que tinha que falar alguma coisa com alguém, então enquanto estou lá sozinha eu ligo e vou falando" (sexo feminino, 16 anos). 
A Tabela 3 indica os efeitos percebidos do uso do celular na satisfação com a amizade e no apoio social recebido e fornecido aos amigos.

Tabela 3

Uso do Celular - Satisfação e Apoio

\begin{tabular}{l|c|c|c}
\hline & Rapazes & Garotas & Total \\
\hline Satisfação - Celular aumentou satisfação com amigos & 8 & 6 & 14 \\
\hline Apoio - Utilizam celular para buscar ou dar apoio aos amigos & 10 & 10 & 20 \\
\hline
\end{tabular}

O aumento da satisfação deve-se à facilitação para encontrar e ser encontrado pelos amigos, aumento no tempo que passam juntos, prazer em receber mensagens ou ligações e planejamento de atividades em conjunto e mesmo a sensação de proteção por não se expor ao amigo, proporcionada pela distância: "sintome mais satisfeita no caso dos meus melhores amigos, porque tem mais opções para conversar com a pessoa" (16 anos). Por outro lado, a ausência física do outro contribui para a falta de satisfação com o uso do celular nas amizades, pela falta do conteúdo não verbal da interação, a insuficiência de recursos para expressar algumas ideias e sentimentos por meio do celular e a insegurança devido à distância e tecnologia (por não saber o que acontece no outro terminal).

$\mathrm{O}$ apoio aos amigos foi emocional (como em momentos de tristeza e para demonstrar preocupação com um amigo), informacional (para obter conteúdos de provas, trocar informações e conhecimentos) e concreto (como conseguir carona, em emergências). Seguem alguns exemplos de apoio emocional: "às vezes você ta muito mal e precisa da pessoa, aí liga pra ela" (sexo feminino, 16 anos). "com o celular, você vê que tem pessoas se importando com você... liga, pergunta como você está, o que vai fazer... pode ser até que a pessoa tenha aquela preocupação, mas com o celular é fácil de você demonstrar" (sexo feminino, 15 anos) "tem como você mandar mensagem pra pessoa, do nada... ah, eu te amo... ah, estou sentindo sua falta... porque você faltou hoje... a qualquer momento você pode mandar uma mensagem, fazer a pessoa sentir que você lembrou dela (...)" (sexo feminino, 16 anos).

A Tabela 4 indica os efeitos do uso do celular na proximidade e na intimidade com amigos.

Tabela 4

O Uso do Celular, Proximidade e Intimidade

\begin{tabular}{|c|c|c|c|}
\hline & Rapazes & Garotas & Total \\
\hline O celular deixou mais próximo dos amigos & 9 & 8 & 17 \\
\hline O celular deixou menos próximo dos amigos & 1 & 2 & 3 \\
\hline O celular aumentou a intimidade com amigos & 4 & 8 & 12 \\
\hline O celular não afetou o nível de intimidade & 6 & 2 & 8 \\
\hline Contam segredos pelo celular & 5 & 6 & 11 \\
\hline Não contam segredos ou confidências via celular & 5 & 4 & 9 \\
\hline
\end{tabular}

Conforme indicado na Tabela 4, os adolescentes percebem aumento na proximidade e na intimidade com os amigos a partir da utilização da telefonia celular, o qual também é utilizado para contar segredos. Em alguns casos, o celular é visto como um instrumento que permite uma comunicação mais personalizada e segura para comunicar assuntos íntimos: "no celular é bem melhor, porque fica mais seguro do que ficar em qualquer outro lugar, do que pessoalmente também" (sexo masculino, 14 anos). Por outro lado, um fator que parece restringir um papel mais expressivo do celular no nível de intimidade é a falta de confiança no meio de comunicação e o receio de invasão de privacidade por meio de escutas ou grampos. "Você tá conversando ali no telefone e acaba falando alguma assim que ela não ia te falar pessoalmente, ou com outra pessoa perto" (sexo feminino, 15 anos). 


\section{DISCUSSÃO}

A presente discussão procura, primeiramente, compreender o conjunto das dimensões investigadas, integrando estas informações. Em seguida, busca comparar estes dados com a literatura, especialmente sobre a amizade de adolescentes.

Apesar do uso do celular permitir a inclusão de novos amigos na rede social dos adolescentes, seu uso afetou mais diretamente as amizades já existentes, provocando aproximação, especialmente para combinar e coordenar atividades em qualquer lugar e a qualquer hora, facilitando a localização e a inclusão no planejamento do grupo, confirmando a tendência de uso descrita por Ling e Yttri (2003). A rede se amplia pouco, mas a comunicação com os amigos já existentes se amplia, diversifica e se aprofunda. $\mathrm{O}$ celular favorece as amizades e as interações antes, durante e após os encontros, mantendo os amigos constantemente informados, sinalizando comprometimento (Hinde, 1997).

Como o celular representa basicamente um meio de comunicação, parte-se das modificações nas comunicações entre os adolescentes e se discute como estas afetaram a estrutura e o funcionamento da rede de amigos (incluindo atividades) e os processos psicossociais presentes na amizade, como satisfação, apoio, proximidade e intimidade. As alterações nos processos de comunicação afetaram diversos aspectos das amizades. As mudanças refletem o desenvolvimento da intimidade tecnológica com o celular entre os adolescentes. Essa interface social (Souza e Silva, 2006) passa a ser responsável por uma parte significativa dos canais de comunicação disponíveis para contato, influenciando oportunidades, duração e temas das conversas, além de provocar mudanças na percepção de disponibilidade e acessibilidade dos indivíduos dentro de sua rede de relacionamentos. A incorporação do celular também redefine os usos de outros canais de comunicação, como a Internet e o telefone fixo, que parecem ser hierarquizados de acordo com a percepção da rede de amigos sobre o nível de identidade que esses outros meios mantêm com o adolescente. À medida que as tecnologias de comunicação tornam-se integradas, os diferentes espaços de interação também são combinados ou sobrepostos. Conforme sugere Hinde (1997), um número maior de interações possibilita mais influências entre as interações e uma exposição maior dos indivíduos na relação, confirmando a importância das tecnologias que aumentam a disponibilidade dos amigos. No entanto, segundo Svaristava (2005), o aumento na quantidade de formas de comunicação entre os indivíduos não necessariamente proporcionaria o aumento na qualidade da comunicação entre eles.

Por outro lado, a ampliação da comunicação é limitada, inclusive pela tecnologia disponível atualmente. Frente à insuficiência de recursos para as interações, como o conteúdo não verbal, Svaristava (2005) e Rivière (2002) relatam a emergência de linguagens próprias de alguns meios de comunicação, com elementos tão ricos em significado quanto às expressões corporais ou articulações verbais. As questões ligadas à segurança ou insegurança nas interações provavelmente apresentariam diferenças significativas caso os celulares já permitissem a transmissão de vídeos ou se a tecnologia fosse considerada totalmente segura, protegida contra clonagem, grampos ou rastreamentos.

Os dados sugerem que o uso do celular como meio de comunicação provoca uma série de efeitos psicossociais, levando a um aumento na satisfação, apoio social, intimidade e proximidade. A discussão procura interpretar como esses vários aspectos se relacionam e se afetam mutuamente. O aumento do tempo, da quantidade e das situações em que a comunicação é possível resulta na percepção do aumento da disponibilidade como a influência mais importante do celular nas amizades. Os ganhos em disponibilidade contribuem para o aumento da satisfação com o relacionamento (Hinde, 1997). Caminhando lado a lado com esses elementos está a ampliação das possibilidades de obtenção e fornecimento de apoio social, abrindo novas frentes para receber e dar apoio, novas oportunidades e novas situações: de madrugada, em emergências, na última hora. A abertura de uma frente mais ampla de comunicação, com a constante atualização de informações entre amigos, ainda contribui para a proximidade e intimidade entre amigos.

Se o celular abre novas possibilidades, algumas destas ainda são limitadas pela natureza desse meio de comunicação. Assim, enquanto as possibilidades de apoio aumentam, há limitações no avanço da intimidade e proximidade em função da falta de confiança na telefonia celular devido ao temor de ausência de privacidade. Este problema limita a autoexposição e o uso do celular como instrumento de aprofundamento 
da intimidade. Por outro lado, algumas limitações da telefonia celular podem facilitar a comunicação para alguns participantes, pela possibilidade de falar sem ser visto.

Assim, a telefonia celular permite um avanço na comunicação com amigos que resulta em amizades potencialmente mais integradas, informadas, satisfatórias, apoiadoras, íntimas e próximas. Apesar disto representar algo positivo do ponto de vista dos relacionamentos, também cria certa dependência da amizade em relação à tecnologia (o mesmo em relação à Internet). Assim, a amizade pode ser afetada pela telefonia celular, como parte como parte da estrutura sócio-cultural e do ambiente físico (Hinde, 1979, 1987, 1997). Porém, a influência é mútua, com o relacionamento interpessoal também demandando mais da tecnologia.

A introdução da telefonia celular leva a uma reorganização dos padrões de comunicação entre os adolescentes, aumentado os recursos que permitem a dois parceiros se manterem atualizados com as ações um do outro, aumentando o conhecimento compartilhado, considerado como elemento essencial da amizade (Hinde, 1997). A comunicação, ponto fundamental das amizades (Feldstein \& Field, 2002), não somente permite maior coordenação de ações, mas também conduz a um aumento da compreensão mútua (Enomoto, 1999). Além disso, provoca mudanças na percepção de outras propriedades do relacionamento, como satisfação, apoio, intimidade e proximidade. $\mathrm{O}$ recurso permite uma reorganização destes aspectos, afetando itens essenciais na amizade como apoio (French, Rianasari, Pidada, Nelwan, \& Buhrmester, 2001), proximidade (Giordano, 1995) e intimidade (Cole \& Bradac, 1996).

Outro ponto que se destaca são as diferenças de gênero sugeridas pelos dados. Rapazes e garotas parecem fazer usos distintos do celular quanto ao conteúdo e à forma da comunicação. As adolescentes possuem celular mais equipado, não usam caixa postal e não perdem chamadas, ligam mais, inclusive de madrugada, e são mais permissivas quanto ao uso do celular pelos amigos. Os participantes do sexo masculino evidenciam conversas mais instrumentais e com propósito definido - sair, obter informações - enquanto as do sexo feminino descrevem uma gama mais aberta de temas, além do planejamento de atividades que também é central nas suas ligações. A existência des- tas diferenças, contudo, é compatível com as diferenças existentes entre as amizades de homens e de mulheres (Hinde, 1997).

\section{CONSIDERAÇÕES FINAIS}

As amizades ganham um novo contorno com o auxílio de novas formas de comunicação, incluindo os telefones celulares, com efeitos principalmente positivos. De modo geral, pode-se dizer que o celular intensifica as amizades do dia-a-dia, ampliando o tempo e as possibilidades de manter-se conectado. Os dados indicam que não se trata de ter-se dois mundos separados, amigos presenciais e amigos pelo telefone, mas a telefonia celular vem complementar e aprofundar as amizades já existentes, não somente marcando e coordenando encontros pessoais, mas também aumentando a quantidade de informações e diversificando as possibilidades de contato, mesmo que este não possa substituir o contato pessoal.

Entre as limitações do presente estudo está a possibilidade de acesso direto ao uso do celular pelos adolescentes, sendo os dados obtidos a partir de relatos desses participantes. O trabalho realizado levanta novos pontos de pesquisa para estudos futuros, como a reação dos adolescentes aos novos recursos disponibilizados (como o envio de fotos, imagens, entre outros), uma maior exploração da dimensão família/pais no uso do celular, em comparação ao uso entre pares, entre outros. O uso (e abuso) das tecnologias de comunicação por adolescentes é um tema amplo e complexo que necessita ser investigado em maior profundidade em nosso meio.

\section{REFERÊNCIAS}

Adams, R., \& Laursen, B. (2001). The organization and dynamics of adolescent conflict with parents and friends. Journal of Marriage and the Family, 63, 97-110.

Adams, R. E., Bukowski, W. M. \& Bagwell, C. (2005). Stability of aggression during early adolescence as moderated by reciprocated friendship status and friend's aggression. International Journal of Behavioral Development, 29, 139-145.

Akers, J. F., Jones, R. M. \& Coyl, D. D. (1998). Adolescent friendship pairs: Similarities in identity status development, behaviours, attitudes, and intentions. Journal of Adolescent Research, 13, 178-201

Allan, G. (2001). Personal relationships in late modernity. Personal Relationships, 8, 325-339.

Bardin, L. (1977). Análise de conteúdo (L. A. Reto \& A. Pinheiro, Trad.). Lisboa: Edições 70. 
Berg, S., Taylor, A. S., \& Harper, R. (2003). Mobile phones for the next generation: Device designs for teenagers. Em Association for Computing Machinery (Org.), Proceedings of the $\mathrm{Hu}$ man Factors in Computing Systems Conference (pp. 433-440). Lauderdale, FL: ACM.

Bolter, J., \& Grusin, R. (1999). Remediation: Understanding new media. Cambridge, MA: MIT Press.

Campbell, S. W., \& Russo, T. C. (2003). The social construction of mobile telephony: An application of the social influence model to perceptions and uses of mobile phones within personal communications networks. Communication Monographs, 70 , 317-334.

Cole, T., \& Bradac, J. (1996). A lay theory of relational satisfaction with best friends. Journal of Social and Personal Relationships, 13, 57-83.

Crothers, L. M., Field, J. E., \& Kolbert, J. B. (2005). Navigating power, control, and being nice: Aggression in adolescent girls' friendships. Journal of Counseling and Development, 83, 349354.

Davide, A., Dario, B., \& Tal, D. (2004) Fashion victims: An unconventional research approach in the field of mobile communication. Retirado de http://newmedia.yeditepe.edu.tr/pdfs/ isimd_04/07.pdf

Souza e Silva, A. (2006). From cyber to hybrid: Mobile technologies as interfaces of hybrid spaces. Space \& Culture, 9, 261278.

Enomoto, J. (1999). Socio-emotional development of friendship among adolescents: Activities with friends and the feeling for friends. Japanese Journal of Educational Psychology, 47, 180190.

Fehr, B. (1996). Friendship processes. Thousand Oaks, CA: Sage.

Feldstein, S., \& Field, T. (2002). Vocal behavior in the dyadic interactions of preadolescent and early adolescent friends and acquaintances. Adolescence, 37, 495-513.

Ferreira, B. E. S., \& Garcia, A. (2008). Aspectos da amizade de adolescentes portadores de diabetes e câncer. Estudos de Psicologia (Campinas), 25, 293-301.

French, D. C., Rianasari, M., Pidada, S., Nelwan, P., \& Buhrmester, D. (2001). Social support of Indonesian and U.S. children and adolescents by family members and friends. Merrill Palmer Quarterly, 47, 377-394.

Garcia, A. (2002). Amizade, enfermidade e deficiência na infância e na adolescência. Pediatria Moderna, 38, 449-452.

Giordano, P. C. (1995). The wider circle of friends in adolescence. American Journal of Sociology, 101, 661-697.

Guattari, F., \& Rolnik, S. (2005). Micropolítica: Cartografias do desejo. Petrópolis: Vozes.

Hinde, R. A. (1979). Towards understanding relationships. London: Academic Press.

Hinde, R. A. (1987). Individuals, relationships and culture: Links between ethology and the social sciences. Cambridge, MA: Cambridge University Press.
Hinde, R. A. (1997). Relationships: A dialectical perspective. Hove, UK: Psychology Press.

Hulme, M., \& Peters, S. (2001, abril). Me, my phone and I: The role of the mobile phone. Trabalho apresentado na Conference on Human Factors in Computing Systems - Workshop on Mobile Communication: Understanding Users, Adoption and Design, Seattle, WA.

Igarashi, T., Taki, J., \& Yoshida, T. (2005). Gender differences in social network development via mobile phone text messages: A longitudinal study. Journal of Social and Personal Relationships, 22, 691-713.

Kasesniemi, E. L., \& Rautiainen, P. (2003). Mobile culture of children and teenagers in Finland. Em J. E. Katz \& M. Aakhus (Orgs), Perpetual contact: Mobile communication, private talk, public performance (pp. 170-192). Cambridge, MA: Cambrigde University Press.

Lannengrand, L. (1998). Adolescence et pairs dans la sphère scolaire: Rapports au groupe-classe et au groupe d'amis chez les collegans. L'Orientation Scolaire et Professionnelle, 27, 235-253.

Lemish, D., \& Cohen, A. (2005) On the gendered nature of mobile phone culture in Israel. Sex Roles, 52, 511-521.

Ling, R., \& Yttri, B. (2003) Hyper-coordination via mobile phones in Norway. Em J. E. Katz \& M. Aakhus (Orgs), Perpetual contact: Mobile communication, private talk, public performance (pp. 139-169). Cambridge, MA: Cambrigde University Press.

Ling, R. (2000) We will be reached: The use of mobile telephony among Norwegian youth. Information Technology and People, 3, 102-120.

Pertierra, R. (2005). Mobile phones, identity and discursive intimacy. Human Technology, 1, 23-44.

Plant, S. (2001) On the mobile: The effects of mobile telephones on social and individual life. Retirado de http://www.moto rola.com/mot/doc/0/234_MotDoc.pdf

Rivière, C. A. (2002). Mini-messaging in everyday interactions: A dual strategy for exteriorising and hiding privacy to maintain social contacts. Revista de Estudios de Juventud, 57, 125-137.

Srivastava, L. (2005) Mobile phones and the evolution of social behaviour. Behaviour \& Information Technology, 24, 112-129.

Truch, A., \& Hulme, M. (2004, junho). Exploring the implications for social identity of the new sociology of the mobile phone. Trabalho apresentado na Communications in the 21st Century Conference, Budapeste.

Urberg, K. A., Degirmencioglu, S. M., \& Tolson, J. M. (1998) Adolescent friendship selection and termination: The role of similarity. Journal of Social and Personal Relationships, 15, 703-710.

Young 'prefer texting to calls' (2003, 13 de junho). BBC News. Retirado de http://news.bbc.co.uk/go/pr/fr/-/2/hi/business/2985 072.stm 


\section{Anexo A}

\section{Questionário sobre Uso do Celular}

\section{Questionário - Uso do Celular}

1) Sobre você:

a) Há quanto tempo você usa o celular?
[ ] Até 1 ano
[ ] 1-3 anos
[ ] 3-5 anos
[ ] Mais de 5 anos

b) Quem comprou o celular que você usa?
[ ] Eu mesmo(a)
[ ] Amigo(a)
[ ] Pais ou Família
[ ] Namorado(a)
[ ] Empresa onde trabalho

c) Quem é responsável pelo pagamento da conta ou compra dos créditos?
[ ] Eu mesmo(a)
[ ] Pais ou Família
[ ] Namorado(a)
[ ] Empresa onde trabalho

d) Quantos minutos em média você fala mensalmente ao celular?
[ ] Até 40 minutos
[ ] 40-80 minutos
[ ] 80-200 minutos
[ ] Mais de 200 minutos

e) Você possui celular primordialmente para:

[ ] Receber chamadas

[ ] Fazer chamadas

f) Quem possui o número do seu celular?
[ ] Todos que pedem
[ ] Todos os meus amigos
[ ] Amigos próximos
[ ] Amigos intimos e familiares
g) Onde você carrega o celular?
[ ] Nas mãos
[ ] Junto ao corpo
[ ] Bolso
[ ] Bolsa, pasta ou mochila

2) Sobre os celulares em geral

a) Você...

[ ] Usa mas não gosta [ ] Usa indiferentemente [ ] Usa e gosta

b) Para você o celular deve ser...

[ ] Funcional [ ] Bonito [ ] Moderno (Recursos) [ ] Barato [ ] Outro:

3) Sobre seu aparelho:

a) Assinale todos os recursos oferecidos pelo seu aparelho:

$\begin{array}{llll}\text { [ ] Tela Colorida } & \text { [ ] Teclado Luminoso } & \text { [ ] Toques Polifônicos } & \text { [ ] Jogos } \\ \text { [ ] ld. de Chamadas } & \text { [ ] Caixa Postal } & \text { [ ] Alarme/Relógio } & \text { [ ] Agenda de Endereços } \\ \text { [ ] WAP/Internet } & \text { [ ] Descanso de Tela } & \text { [ ] Câmera Digital } & \text { [ ] Mensagens de Texto } \\ \text { [ ] MP3 Player } & \text { [ ] Infra-Vermelho } & \text { [ ] Bluetooth } & \text { [ ] Mensagens Multimídia }\end{array}$

b) Indique o recurso mais utilizado por você diariamente:
[ ] Chamadas de voz
[ ] Mens. de Texto
[ ] Mens. Multimídia
[ ] Jogos
[ ] Câmera Digital
[ ] Agenda
[ ] Caixa Postal
[ ] WAP/Internet 
4) Sobre a comunicação com seus amigos(as):

a) Em quais situações você não atenderia uma ligação dos seus amigos(as)?

$\begin{array}{llll}\text { [ ] Refeições } & \text { [ ] Reuniões Familiares } & \text { [ ] Banho } & \text { [ ] Madrugada } \\ \text { [ ] Transporte Público } & \text { [ ] Filas } & \text { [ ] Aula } & \text { [ ] Quando estou namorando } \\ \text { [ ] Trabalho } & \text { [ ] Balada } & \text { [ ] Viagem } & \text { [ ] Outro: }\end{array}$

b) Em quais situações você não ligaria para seus amigos(as)? (Marque quantas desejar)

$\begin{array}{llll}\text { [ ] Refeições } & \text { [ ] Reuniões Familiares } & \text { [ ] Banho } & \text { [ ] Madrugada } \\ \text { [ ] Transporte Público } & \text { [ ] Filas } & \text { [ ] Aula } & \text { [ ] Ele(a) estiver namorando }\end{array}$

[ ] Trabalho [ ]Balada [ ] Viagem [ ] Outro:

c) Em relação aos meus amigos(as):

[ ] Eu telefono mais vezes [ ] Eu recebo mais telefonemas

d) Para os meus amigos(as) eu...

[ ] Apenas telefono [ ] Telefono e envio torpedos [ ] Telefono, envio torpedos e fotos

e) Dos meus amigos(as) eu recebo...

[ ] Apenas ligações [ ] Ligações e torpedos [ ] Ligações, torpedos e fotos

f) Os celulares dos meus amigos(as) são...

[ ] Similares ao meu [ ] Melhores que o meu [ ] Inferiores ao meu [ ] Não sei

g) Você informaria o telefone dos seus amigos(as) para...

[ ] Qualquer um [ ] Amigos do seu amigo [ ] Amigos em comum [ ] Amigos intimos e familiares

h) Quando você usa o celular dos seus amigos(as)?

[ ] Nunca [ ] Emergências [ ] Quando o meu não funciona [ ] Às vezes [ ] Sempre

i) Meus amigos(as) podem... (Marque quantas desejar)

[ ] Atender minhas ligações [ ] Ouvir minha caixa postal [ ] Ler torpedos que mandei

[ ] Ver chamadas que eu fiz [ ] Ver chamadas que eu recebi [ ] Ler torpedos que recebi

[ ] Ver as fotos que recebi [ ] Ver as fotos que mandei [ ] Ver minha fatura

[ ] Sair com o meu celular [ ] Viajar com meu celular [ ] Emprestar meu celular

5) Indique a operadora, a marca e o modelo do seu celular: 


\section{Anexo B \\ Roteiro de Entrevista}

\section{Roteiro de Entrevista}

1. O uso do celular alterou, de alguma forma, o número de amigos que você possui?

2. O uso do celular alterou seu grupo de amigos?

3. O celular permitiu que você tivesse amigos que antes você não tinha? Por quê?

4. Como o celular afeta para combinar, realizar e depois avaliar as atividades que você desenvolve com seus amigos? Por quê? (Usar exemplo da ida ao cinema)

5. Com que frequência você usa o celular para combinar atividades com seus amigos?

6. O celular mudou a forma de você entrar em contato com seus amigos? Como?

7. Quando, ou em que situações, você liga para seus amigos?

8. Quanto tempo, em média, dura uma ligação para um amigo? Por quê?

9. O celular afetou, de alguma forma, os temas das conversas com seus amigos? Como?

10. Quais são os principais assuntos que você fala com seus amigos ao celular?

11. O celular alterou a quantidade de informação trocada com seus amigos?

12. Pensando na média de minutos que você conversa com seus amigos diariamente, você acha que esse tempo aumentou o diminuiu com o celular? Por quê?

13. Você acha que o celular proporcionou novas oportunidades de contato com seus amigos que você não tinha antes? Quais?

14. Qual a principal forma de contato com seus amigos através do celular? Voz, torpedos ou multimídia? Por quê?

15. Você acha que o celular mudou o nivel de intimidade que você tinha com seus amigos? Por quê?

16. Você conta segredos ou troca confidencias pelo celular? Por quê? Utilizando voz ou torpedos?

17. O que você não conversaria com seus amigos pelo celular? Por quê?

18. Você acha que o celular te deixou mais próximo dos seus amigos? Por quê?

19. Considerando todas as formas disponíveis para conversar com seus amigos, você acha que o uso do celular representa quantos por cento do total? Por quê?

20. Se não conseguir falar com seu amigo ao celular, qual seria a segunda forma de contato que você tentaria? Por quê?

21. Quais são os pontos negativos da comunicação com seus amigos pelo celular? Por quê?

22. Quais são os pontos positivos da comunicação dos seus amigos pelo celular? Por quê?

23. O celular aumentou o diminuiu a satisfação com suas amizades? Por quê?

24. Para qual amigo você mais liga? Por quê? Você acha que é a pessoa para quem esse seu amigo mais liga? Por quê?

25. Você poderia dizer quais as influências mais importantes do celular em suas amizades? 